\title{
O Benefício de Prestação Continuada para usuários em tratamento hemodialítico
}

\author{
The Continued Benefit to users in hemodialysis
}

\author{
Nathalia Maria Barbosa * \\ Raquel Cavalcante Soares** \\ Ilka Aquino de Oliveira Perusso ${ }^{* * *}$
}

\section{Resumo:}

Os usuários em hemodiálise afastam-se do trabalho por fatores que envolvem o tratamento e o mundo do trabalho. Essa situação é um agravante para os não segurados da previdência social. Para esses, só restam o Benefício de Prestação Continuada (BPC), como o único meio de acesso à renda. Contudo, ao acessá-lo confrontam-se com algumas contradições. Este artigo analisa as contradições e dificuldades no acesso ao benefício.

Palavras-chave: Hemodiálise; Benefício; Assistência social.

\begin{abstract}
:
User's hemodialysis move away from work for factors involving the treatment and the world of work. This situation is an aggravating factor for the uninsured social security. For these, we have only the Continuous Cash Benefit (BPC), as the only means of access to income. However, when accessing it are faced with some contradictions. This article analyzes the contradictions and difficulties in access to the benefit.
\end{abstract}

Keywords: Hemodialysis; Benefit; Social assistance.

\section{Introdução}

A doença renal crônica (DRC) é uma lesão renal caracterizada pela perda lenta, progressiva e irreversível da função dos rins. Estima-se que, no Brasil, um em cada 5.000 pessoas tenha a função renal comprometida (SBN, 2011). Nas últimas décadas, essa doença

\footnotetext{
* Assistente social residente do Programa de Residência Multiprofissional Integrada em Saúde - PRMIS na área de concentração nefrologia do Hospital das Clínicas da Universidade Federal de Pernambuco - HC/UFPE. E-mail: nathalia.as11@gmail.com

** Doutora em Serviço Social. Professora do Departamento de Serviço Social da Universidade Federal de Pernambuco - UFPE. E-mail: quelcsoares@gmail.com

*** Assistente social do Hospital das Clínicas da Universidade Federal de Pernambuco - HC/UFPE. Mestre em Serviço Social. E-mail: $\underline{\text { llka aquino@ig.com.br }}$
} 
tem se apresentado como um problema mundial de saúde pública, pelo aumento progressivo de sua taxa de incidência e prevalência, além de elevada morbimortalidade, sendo considerada na contemporaneidade uma epidemia de crescimento alarmante.

Esse caráter epidêmico se justifica, em parte, pelo expressivo crescimento no número de casos de diabetes mellitus e hipertensão arterial, bem como pelos maus hábitos de vida da população (ROMÃO JÚNIOR, 2009). Posto que, as modificações nos hábitos de vida das pessoas (alimentação com alto consumo de sódio, uso abusivo de medicação, sedentarismo etc.) levam ao surgimento/agravamento das consideradas doenças da modernidade (hipertensão, diabetes, estresse etc.), aumentando, dessa forma, as doenças crônico-degenerativas, entre elas a DRC.

Quando a DRC esta em seu estágio mais avançado precisa-se de terapias renais substitutivas (TRS) - hemodiálise, diálise peritoneal ou transplante - necessárias para a manutenção da vida do indivíduo, sendo que, no Brasil, a maioria deles se encontra na modalidade de hemodiálise ${ }^{1}$ (ROMÃO JÚNIOR, 2009).

Segundo dados da Sociedade de Nefrologia do Estado de São Paulo (SONESP), o número de pessoas que se encontram na modalidade de hemodiálise vem crescendo nos últimos anos, passando de 500, em 1976, para 9 mil, em 1986, chegando aos 95 mil, em 2008. O número de novos usuários cresce $9 \%$ ao ano, e, apesar do forte crescimento, estimativas apontam que, dos 150 mil brasileiros que precisam fazer hemodiálise, apenas 90 mil estão em tratamento, seja pelo desconhecimento da doença, seja por falta de unidades de atendimento (SONESP, 2009).

Os referidos dados traduzem o avanço crescente no número de usuários em hemodiálise no país. Esse crescimento nos leva a refletir acerca da condição de saúde, bem como dos determinantes sociais que incidem na vida dessas pessoas - como o trabalho, a renda, a alimentação, a habitação, o saneamento, a educação, o transporte, o lazer, entre outros - que influenciam diretamente na qualidade e manutenção da saúde.

\footnotetext{
${ }^{1}$ A hemodiálise é um processo de circulação sanguínea extracorpórea, em que o sangue é removido para fora do corpo, passando por dentro de um dialisador (membrana artificial) para ser filtrado e assim serem removidas as toxinas e líquidos retidos no sangue, cuja função renal não conseguiu excretar. Esse procedimento pode ser realizado em hospitais ou clínicas de diálise, realizado, geralmente, três vezes por semana durante quatro horas cada sessão (SBN, 2011).
} 
Esses determinantes sociais, quando ocorrem de forma precária, remetem a uma condição de vida precarizada que se relaciona, entre outras coisas, às dificuldades de acesso aos serviços públicos em geral e de saúde em particular. Inúmeros estudos mostram que aqueles que vivem em piores condições de vida são exatamente os que, embora certamente mais necessitados, têm pior acesso a políticas públicas.

Um estudo realizado junto a usuários no serviço de hemodiálise de um hospital público de Minas Gerais constatou que os usuários do serviço, em sua maioria, eram pessoas pauperizadas, com menor escolaridade, com maior tempo em hemodiálise e pior acesso ao tratamento com nefrologista. Diante disso e de outros aspectos analisados, esse estudo concluiu que os determinantes sociais como trabalho, renda, alimentação, habitação, saneamento e educação influenciam na evolução da doença renal crônica (MARTINEZ et al., 2011).

Nesse sentido, percebemos que há um processo de determinação social nos altos índices de adoecimento por DRC, como também nas condições de acesso ao tratamento. De fato, considera-se que as condições de vida vão contribuir decisivamente para o adoecimento, como também para a sua evolução e para o tratamento da doença, conforme a concepção ampliada de saúde preconizada pela reforma sanitária brasileira. ${ }^{2}$

Entre os determinantes sociais, o trabalho tem uma representação importante no processo saúde-doença, uma vez que se constitui categoria fundante da sociabilidade humana, é ele que torna possível a produção de qualquer bem, criando os valores que constituem a riqueza social, tornando-se central a partir de sua atuação na natureza ${ }^{3}$, produzindo, reproduzindo e transformando sua vida. O trabalho para o homem faz parte da vida social e da sua realização individual, ao mesmo tempo que se encontra relacionado aos processos de precarização das condições de trabalho e superexploração dos trabalhadores (ANTUNES, 1995).

\footnotetext{
${ }^{2}$ Segundo os preceitos da reforma sanitária, a saúde, muito mais que ausência de doença, é o resultado das condições objetivas e subjetivas que propiciam uma vida digna. Essa concepção de saúde assumiu que o adoecimento da população é diretamente influenciado pelo contexto social resultante das condições de vida dos sujeitos. O que significa dizer que a produção da saúde da população depende do conjunto das políticas públicas (BUSS; PELLEGRINI FILHO, 2007).

${ }^{3}$ Conforme Luckács $(1979$, p. 3), o ser social só se desenvolve a partir de um contato com o ser orgânico - a natureza - e, ao modificá-lo, auto modifica-se também adquirindo novas habilidades e conhecimentos, sendo durante esse processo que se desenvolvem a história humana e as relações sociais.
} 
No entanto, a falta do trabalho ou o não trabalho representa na sociedade uma expressão da questão social, que afeta diretamente a vida das pessoas, posto que o trabalho, por ser, sobretudo, gerador de renda, insere-se num espaço de produção material indispensável à sobrevivência.

Partindo do pressuposto de que o trabalho e, consequentemente, a renda são determinantes fundamentais do processo saúde-doença, problematizamos o acesso à renda dos usuários em terapia hemodialítica do Hospital das Clínicas da Universidade Federal de Pernambuco (HC-UFPE), especificamente no que se refere ao benefício da assistência social denominado BPC - Benefício de Prestação Continuada.

No último levantamento socioeconômico realizado junto aos usuários em tratamento hemodialítico no HC-UFPE, no ano de 2007, identificou-se que 95,9\% dos usuários não exerciam atividade remunerada; $83,7 \%$ tinham sua renda vinculada a algum benefício da previdência ou da assistência social, dos quais 38,6\% recebiam o BPC (OLIVEIRA; SEVERO; NASCIMENTO, 2008). Diante disso, observamos que grande parte dos usuários não tinha acesso ao trabalho formal assalariado e não contribuía com a previdência social, portanto, não teve direito à proteção previdenciária no momento da inserção na terapia hemodialítica. E, nesse sentido, o BPC tornou-se o único meio possível de acesso à renda para esses usuários.

No entanto, os critérios de acesso para a obtenção do BPC são considerados seletivos e focalizados os de extrema pobreza. Para a inserção no benefício, o usuário deve ser idoso (maior de 65 anos) ou portador de deficiência; precisa comprovar renda per capta familiar de até $1 / 4$ do salário mínimo; e não ser beneficiário da previdência social.

Assim, o BPC se configura um benefício de acesso restrito. Portanto, compreender o processo de inserção dos usuários do serviço de hemodiálise do HC-UFPE no referido benefício e a importância deste para a sua reprodução social torna-se questão fundamental para o entendimento das condições de saúde desses sujeitos. Ademais, a relevância do presente estudo encontra-se no fato de que seus resultados servirão para dar visibilidade às expressões da questão social implicadas no processo saúde-adoecimento dos usuários em hemodiálise.

O presente artigo fundamenta-se teórico-metodologicamente na teoria social crítica marxiana, fazendo uso de categorias como trabalho, contradição, Estado e política social 
como expressões contraditórias da luta de classes na sociedade civil, entre outras. Nesse sentido, analisaremos o acesso ao benefício da assistência social nos seus avanços e retrocessos, situado em meio às contradições, à correlação de forças e às necessidades sociais do capitalismo na contemporaneidade.

O artigo se desenvolve em cinco momentos: no primeiro, fazemos uma contextualização das problemáticas enfrentadas pelos usuários em tratamento hemodialítico; no segundo, conceituamos a assistência social e o BPC; no terceiro, discutimos as principais tendências apresentadas pela assistência social, em especial pelo BPC, nos últimos anos; no quarto, demonstramos a metodologia utilizada para a realização da pesquisa; e no quinto, realizamos uma análise do perfil dos entrevistados, do processo de inserção no benefício e da importância deste para a reprodução social dos usuários em hemodiálise no HC-UFPE.

\section{Problemáticas dos usuários em tratamento hemodialítico}

A hemodiálise é um tipo de tratamento para pessoas que sofrem de doença renal crônica (DRC), caracterizada pela perda irreversível da função dos rins. A DRC consiste num problema clínico significante, que se apresenta por sintomas como fadiga, emagrecimento, náusea, edema, palidez cutânea, sonolência, hipertensão arterial, desequilíbrio dos níveis de cálcio e de fósforo, anemia, entre outros (RIBEIRO et al., 2008). Devido o seu caráter crônico, a doença não tem expectativa de cura, mas da manutenção do estado de cronicidade.

Com o diagnóstico da doença, todas as condutas necessárias para o tratamento (controle da alimentação e da ingestão hídrica, uso de medicamentos, consultas clínicas, realização de diálises etc.) passam a ser contínuas.

Nesse sentido, os usuários com DRC, desde o diagnóstico, deparam-se com uma série de perdas que vão além da perda da função renal e se relacionam a questões de âmbito socioeconômico como: perda do emprego, isolamento social, dependência da seguridade social, parcial impossibilidade de locomoção, entre outras situações (PALOMBINI; MANFRO; KOPSTEIN, 1985).

Sendo assim, a condição da doença e o tratamento hemodialítico, geralmente, acarretam mudanças na rotina de vida desses usuários, devido, principalmente, ao desgaste 
físico após as sessões de hemodiálise (deixando-o frágil para exercer atividades que exijam esforço físico) e ao longo tempo que fica conectado à máquina (limitando o tempo diário nos dias de tratamento).

Dessa forma, eles vivenciam mudanças na sua vida que refletem problemas diversos que acabam interferindo no seu modo de vida, ademais, estão propensos a efeitos colaterais clínicos ${ }^{4}$ inerentes à própria terapia hemodialítica. Unruh et al. (2003) colocam que, mesmo diante dos avanços terapêuticos e tecnológicos que permitem aumento na sobrevida, em relação aos aspectos qualitativos não há muitas possibilidades de retorno à vida habitual.

Diante disso, é possível inferir que os usuários que realizam hemodiálise enfrentam limitações cotidianas que impactam nas suas atividades habituais, entre elas o trabalho. E, por isso, na maioria das vezes, precisam se afastar do trabalho em função da rotina imposta pelo tratamento, em decorrência dos efeitos colaterais clínicos, bem como do tempo exigido para o tratamento, o qual dificulta a manutenção em atividades paralelas diárias, tendo em vista que eles têm o compromisso de comparecer às sessões de hemodiálise, geralmente, três vezes na semana durante quatro horas, em dias alternados.

Manter-se num trabalho requer tempo para o cumprimento da jornada de trabalho e habilidade para o desempenho das atividades, exigências impostas pela lógica do mercado de trabalho, que com a reestruturação produtiva tende a precarizar as relações de trabalho; intensificar o ritmo da exploração; diminuir os postos de trabalho, exigindo do trabalhador: superqualificação, polivalência, disponibilidade de superexploração, entre outras. Diante disso, a continuidade desses usuários no exercício da atividade remunerada, de fato, torna-se algo difícil, tendo em vista não apenas as limitações impostas pelo tratamento, mas, também, as particularidades históricas do mercado de trabalho brasileiro.

Particularidades históricas influenciadas pela lógica atual da acumulação flexível, que se caracteriza por: constantes flutuações do mercado; aumento da competição; redução do poder aquisitivo do trabalhador; e enfraquecimento do poder sindical, resultando no

\footnotetext{
${ }^{4}$ No tratamento hemodialítico é bastante comum as pessoas apresentarem: dor e fraqueza nos ossos, fraqueza muscular e hipotensão. Levando a sintomas como: cãibras musculares, fraqueza, tonturas, enjoos, vômitos etc. (SBN, 2011).
} 
desemprego estrutural e na exclusão de trabalhadores do mercado de trabalho (SOARES, 2000).

Sob relações capitalistas de exploração, Marx (1984) afirma que o trabalho produz alienação, destitui o homem da propriedade de sua força de trabalho, e obriga o trabalhador a submeter-se a atividades ignóbeis a qualquer preço.

Diante dessas particularidades históricas do mercado de trabalho brasileiro, compreendemos a dificuldade enfrentada pelos usuários em tratamento hemodialítico para manter-se trabalhando, seja no mercado formal, seja no informal, uma vez que o mundo industrializado, com a lógica da acumulação flexível, dificulta a permanência do trabalhador em qualquer tipo de trabalho.

Sendo assim, é pertinente observarmos que o afastamento das atividades remuneradas se torna um agravante àqueles que são trabalhadores informais, isto é, sem proteção previdenciária, e, por isso, sem direitos que garantam a manutenção da sua renda enquanto estiverem em tratamento hemodialítico. Para esses desprotegidos da previdência, só lhes restam a assistência social, especificamente o BPC, como único meio possível de acesso à renda.

Diante do que foi exposto, é possível perceber os aspectos peculiares da pessoa com DRC em tratamento hemodialítico, evidenciando-se a necessidade de articulação entre saúde e assistência social.

\section{A política de assistência social e o BPC}

As ações de assistência e enfrentamento da pobreza nem sempre estiveram vinculadas ao direito de cidadania. De acordo com Mota (2000), a assistência social no Brasil se caracterizou por três momentos históricos; no primeiro momento a assistência era vista como caridade, vinculada à ideia de ajuda; no segundo momento era vista como favor do Estado (quando a demanda das necessidades aumentava devido às contradições capitalistas, e o Estado passava a intervir de forma assistencialista) que se caracterizava como o acesso a um bem que era efetivado por meio de doação do Estado; e no terceiro momento, a assistência se afirmou enquanto direito do cidadão e dever do Estado, e assumiu o status formal como política que compõe a seguridade social. 
A Constituição Federal de 1988 foi o marco central da proteção social brasileira, sobretudo por ter instituído a seguridade social (composta pelas políticas de assistência social, previdência social e saúde). Dessa forma, a presente constituição alterou o quadro da proteção social com expressivos impactos em termos de ampliação da cobertura. A assistência social foi institucionalizada e passou a fazer parte do orçamento público, não mais subordinado à filantropia, como nos anos anteriores, mas como um direito social, assim como o benefício que integra esta política.

O BPC é instituído pela Constituição de 1988 no art. 203 e regulamentado pela Lei 8.742/93, Lei Orgânica da Assistência Social - LOAS (BRASIL, 1993), mas sua implantação só ocorre em 1996 com a extinção da Renda Mensal Vitalícia (RMV) ${ }^{5}$, o qual era um beneficio "assistencial" da previdência, que teve um significado importante por ter contribuído para a redução da pobreza absoluta dos idosos e das pessoas com deficiência. Entretanto a sua substituição pelo BPC foi considerada um grande avanço, por este representar uma perspectiva mais inclusiva, ultrapassando a visão restrita do contrato que garantia acesso apenas a cidadãos contributivos.

$\mathrm{O}$ BPC é reconhecido como um benefício não contributivo, destinado à pessoa portadora de deficiência e ao idoso, desde que comprovem não possuir meios de prover a própria manutenção ou de tê-la provida por sua família. Constitui-se como uma transferência direta de renda, garantindo o valor mensal de um salário mínimo, conforme dispõe a LOAS/93. Para a inserção no BPC, o usuário deve estar dentro dos critérios, são eles: ser idoso (maior de 65 anos) ou portador de deficiência; ter renda familiar per capta inferior a 1/4 (um quarto) do salário mínimo, e não estar recebendo nenhum benefício da Previdência Social ${ }^{6}$.

Este benefício é um direito social que integra a proteção social básica no âmbito do Sistema Único da Assistência Social (SUAS), sua gestão é realizada pelo Ministério do Desenvolvimento Social e Combate à Fome (MDS), por intermédio da Secretaria Nacional

\footnotetext{
${ }^{5}$ Criada por meio da Lei no 6.179/74 como benefício previdenciário destinado às pessoas maiores de 70 anos de idade ou inválidos, definitivamente incapacitados para o trabalho, que, em um ou outro caso, não exerciam atividades remuneradas e não auferiam rendimento superior a $60 \%$ do valor do salário mínimo. Além disso, não poderiam ser mantidos por pessoas de quem dependiam, bem como não poderiam ter outro meio de prover 0 próprio sustento (BRASIL, 2013).

${ }^{6}$ Ressalvados o de assistência médica e a pensão especial de natureza indenizatória, bem como a remuneração advinda de contrato de aprendizagem no caso da pessoa com deficiência (BRASIL, 2013).
} 
de Assistência Social (SNAS), que é responsável pela coordenação, regulação, financiamento, monitoramento e avaliação do benefício. No entanto, a operacionalização é realizada pelo Instituto Nacional do Seguro Social (INSS), o qual realiza perícia, avaliação e concessão dos casos. Os recursos para o custeio do BPC provêm da assistência social, sendo administrado pelo MDS e repassado ao INSS, por meio do Fundo Nacional de Assistência Social (FNAS).

Os usuários em tratamento hemodialítico, embora não sejam considerados pessoas com deficiência, podem conseguir a inserção no BPC por terem impedimentos corporais que acarretam em limitações nas atividades, conforme descrito anteriormente. Eles se enquadram no atual conceito da Classificação Internacional de Funcionalidade $(\mathrm{CIF})^{7}$, que considera a pessoa com deficiência aquela que tenha limitações para atividades, participação e integração social (MEDEIROS, 2007).

Entretanto, o BPC, diante da especificidade do mercado de trabalho brasileiro, marcado pela informalidade, buscou inserir a diversidade das situações sociais vigentes no atual modelo de sociedade capitalista. No entanto, sua implementação, como um direito social, apresenta movimentos de avanços e retrocessos, como analisaremos.

\section{Atuais tendências da assistência social e do BPC}

A assistência social, política pública não contributiva, é dever do Estado e direito de todo cidadão que dela necessitar. Segundo a LOAS/93 deve se configurar por atender às necessidades básicas àqueles que não têm condições de provê-las, isso se dá por meio de ações de prevenção e provimento de um conjunto de garantias e seguranças que cubram, reduzam ou previnam exclusões, riscos e vulnerabilidades sociais, bem como atendam às necessidades emergentes ou permanentes. Tais ações devem chegar ao usuário de forma que estes e suas famílias obtenham aquisições materiais, sociais, socioeducativas e assim possam suprir suas necessidades de reprodução social.

\footnotetext{
${ }^{7} \mathrm{O}$ atual conceito de deficiência pela Classificação Internacional de Funcionalidade (CIF) define a pessoa com deficiência sendo aquela incapaz para a vida independente e para o trabalho, pois deficiência é o resultado da relação entre um corpo com impedimentos e a sociedade, ou seja, a deficiência é avaliada com base na participação de uma pessoa com impedimentos corporais na vida social (MEDEIROS, 2007).
} 
Entretanto, a política de assistência social por ser contraditória e limitada pode assumir tanto o aspecto de concretização dos direitos sociais quanto ser favorável à acumulação do capital e à manutenção da lógica do lucro.

Segundo lamamoto (2001), nenhuma política social, no modo de produção capitalista, pode ter o caráter de garantia plena da equidade social. Há que se considerar, o caráter contraditório das políticas sociais, posto que por um lado elas representam parcial resposta às reivindicações da classe trabalhadora, e por outro elas reforçam e legitimam a lógica mercadológica do capital.

Nesse sentido, é possível confirmar o caráter ambíguo da política de assistência social, no qual ao mesmo tempo que se busca garantir a satisfação das necessidades básicas tem-se uma política restritiva, seletiva e focalista.

Dessa forma, as ações da assistência social - embora sejam destinadas a reduzir ou prevenir exclusões, riscos e vulnerabilidades sociais - não alcançam esses objetivos em sua plenitude, já que suas ações se restringem a grupos sociais específicos e, sobretudo, condicionados ao nível de renda, em que o acesso a serviços e benefícios se operacionaliza pela focalização e seletividade.

No caso dos benefícios, em especial o BPC, o critério de inserção se dá pela seleção do mais necessitado economicamente. Por essa lógica operacional, o acesso ao BPC acaba se dando pela via do mínimo e da subsistência. Essa situação exclui aquele usuário que precisa do benefício, mas que não consegue responder aos critérios para a sua inserção, por não atingir o limiar da extrema pobreza.

Sendo assim, a seletividade para a inclusão no BPC dificulta o acesso, bem como a focalização deste, que se destina àqueles absolutamente incapazes de prover sua subsistência, os quais estão em situação de vulnerabilidade social praticamente irreversível (PEREIRA, 2002).

Em consonância, Ivo e Silva (2011) afirmam que mesmo no campo de um direito constitucional básico, como o BPC, a seletividade estrutural opera esse benefício deixando de fora dos direitos básicos de cidadania um grande contingente de cidadãos, por rebaixar a linha de pobreza brasileira ao status de indigência, escamoteando os reais objetivos da política de assistência social. 
Mesmo quando o cidadão consegue o acesso ao benefício, ainda assim permanece com dificuldades, posto que o valor do benefício (um salário mínimo) não consegue modificar significativamente a realidade das famílias que se encontram em precárias condições de vida. Segundo Netto (1999), são recursos mínimos destinados a pessoas incapazes de prover sua subsistência, cuja característica se torna pobre políticas sociais para os pobres.

Para Pereira (2002), essa focalização aponta a fragilidade do princípio da assistência social, que tem se caracterizado por ações que contrariam o direito social. Sendo assim, é possível compreender que a focalização do benefício, uma vez que exige uma renda familiar per capta muito baixa, seleciona o mais pobre dentre todos os pobres. E com isso excluem pessoas que não atendem aos critérios exigidos, mas que necessitam do benefício para se reproduzirem socialmente.

Nesse sentido, a focalização do benefício reverte ou reduz padrões de proteção social por deixar de fora alguns cidadãos que não se enquadram nos critérios de elegibilidade do BPC e não integram os direitos securitários da previdência social, consequentemente, distanciam-se de garantir à sociedade o acesso à seguridade social de qualidade.

\section{Método}

O presente artigo fundamenta-se teórico-metodologicamente na teoria social crítica Marxiana, por meio de levantamento bibliográfico e pesquisa de campo a partir da abordagem qualitativa, a qual trabalha com valores, crenças, hábitos, atitudes, representações, opiniões e adequa-se a aprofundar a complexidade de fatos e processos particulares e específicos a indivíduos e grupos (MINAYO, 1993).

A pesquisa foi realizada no serviço de hemodiálise do HC-UFPE em obediência a Resolução no 196 de 10 de outubro de 1996 que dispõe sobre as Diretrizes e Normas Regulamentadoras de Pesquisas Envolvendo Seres Humanos (BRASIL, 1996). Submetida à análise do Comitê de Ética em Pesquisa do Centro de Ciências da Saúde da Universidade Federal de Pernambuco CCS/UFPE.

A presente pesquisa utilizou como instrumento de coleta de dados a entrevista estruturada com questões abertas e fechadas, realizadas no mês de abril de 2013, durante 
o período de 30 dias, tendo como critério de inclusão usuários em tratamento hemodialítico no HC/UFPE inseridos no Benefício de Prestação Continuada.

Foram selecionados 19 usuários do serviço que se encontravam dentro dos critérios de inclusão. A participação dos entrevistados foi voluntária, por meio da assinatura do Termo de Consentimento Livre e Esclarecido (TCLE). As entrevistas foram realizadas na sala da hemodiálise, enquanto os usuários dialisavam, esse tipo de procedimento é comum nesse setor, utiliza-se desse tempo que o usuário esta conectado à máquina para responder às demandas, tendo como objetivo otimizar o tempo, deixando-o mais produtivo para o usuário e para a equipe.

\section{Perfil socioeconômico dos usuários em hemodiálise inseridos no BPC}

Em consonância às tendências apresentadas pelo BPC, os dados da pesquisa revelam a realidade da situação socioeconômica dos usuários em tratamento hemodialítico no HCUFPE inseridos no benefício.

Dentre os entrevistados, foi identificado que a maioria deles tem baixo nível de escolaridade e uma baixa condição econômica, como observamos na tabela 1:

Tabela 1 - Caracterização dos entrevistados quanto à escolaridade e renda antes do tratamento hemodialítico. Recife, HC/UFPE, 2013.

\begin{tabular}{lcc}
\hline \multicolumn{1}{c}{ Características } & $\mathbf{N}$ & Entrevistados (N=19) \\
\cline { 2 - 3 } & 3 & $\%$ \\
\hline Nível educacional & 12 & 16 \\
Não alfabetizado & 4 & 63 \\
Fundamental & 0 & 21 \\
Médio & & 0 \\
Superior & 3 & \\
Renda individual & 3 & 16 \\
Sem renda & 13 & 16 \\
Inferior a 1 salário mínimo & & 68 \\
Igual a 1 salário mínimo & 19 & 100 \\
\hline TOTAL &
\end{tabular}

Fonte: Elaborada pelas autoras.

Levando em consideração que o grau de escolaridade tem fortes relações com a condição econômica, esses dados evidenciam que tais usuários se encontram em situação de vulnerabilidade social, posto que o baixo nível de escolaridade e a baixa condição 
econômica são fatores que interferem na reprodução social dos sujeitos. Assim, essa escolaridade apresentada expressa a precariedade e a dificuldade em acessar a educação formal, o que possivelmente interferiu no acesso à informação adequada sobre o processo saúde-doença e na atuação de acordo com essas informações, como, também, a sua baixa condição econômica, que antes mesmo de iniciar o tratamento hemodialítico, já apresentava dificuldades para a manutenção das necessidades vitais básicas ${ }^{8}$, o que nos leva a inferir que os fatores aqui analisados, quase sempre, acarretam em sérios rebatimentos na qualidade de vida e saúde desses usuários.

Portanto, educação e renda são determinantes sociais que incidem na saúde dos sujeitos. Esses fatores associados trazem repercussões não só para a saúde, mas também para a inserção no mercado de trabalho.

Nesse sentido, avaliando os dados apresentados, verificamos que o nível de escolaridade, bem como o nível econômico dos usuários reproduz na composição de suas profissões. Identificamos que a condição econômica tem fortes relações com o grau de escolaridade que também se relaciona à inserção ou não no mercado de trabalho e ao tipo de trabalho (formal ou informal), como podemos constatar a seguir, com o gráfico 1:

Gráfico 1 - Inserção no mercado de trabalho antes e depois da terapia hemodialítica. Recife, HC/UFPE, 2013.

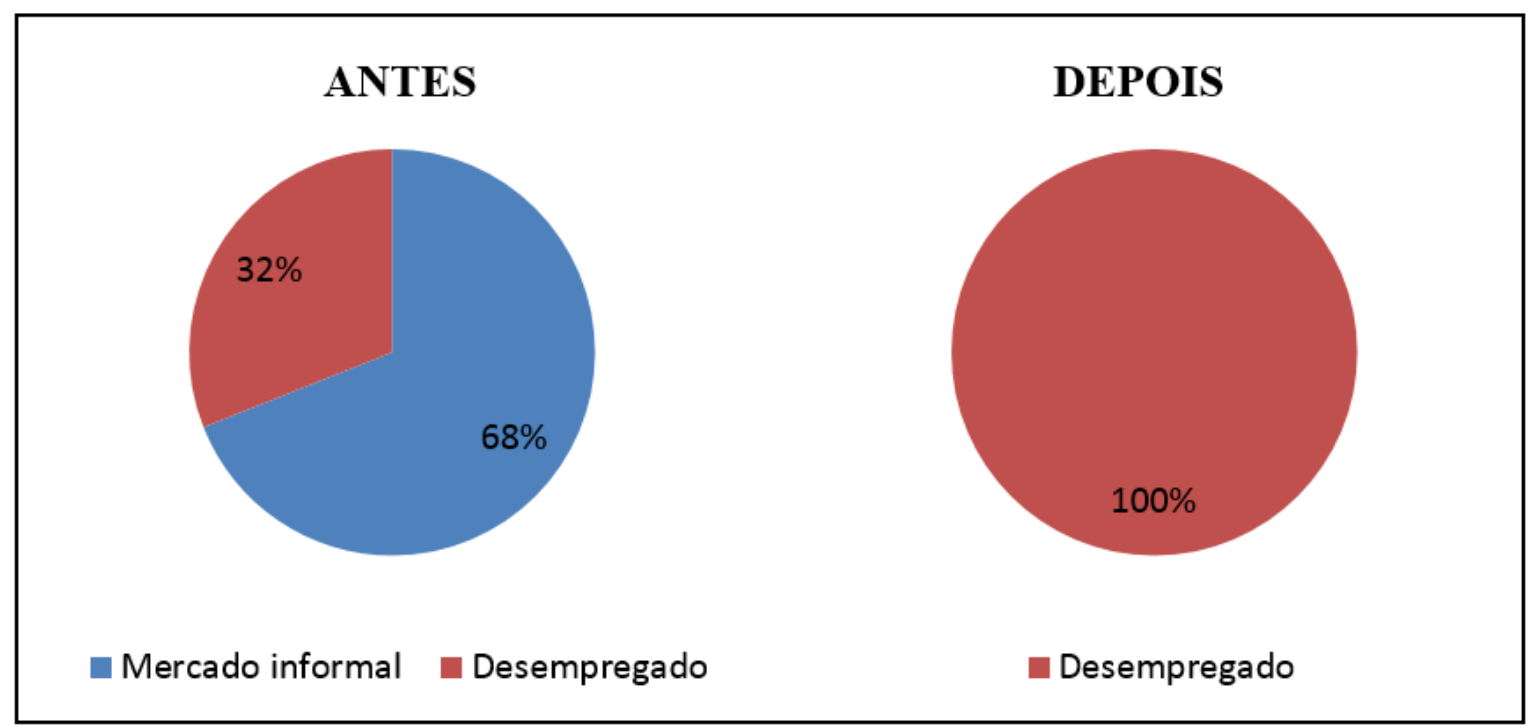

Fonte: Elaborado pelas autoras.

\footnotetext{
${ }^{8}$ Segundo a Constituição Federal de 1988 as necessidades vitais básicas de uma família são: alimentação, moradia, saúde, educação, vestuário, higiene, transporte, lazer e previdência social (BRASIL, 2006).
} 
Esse gráfico mostrou que $68 \%$ (13) trabalhavam informalmente antes do adoecimento; e 32\% (6) não exerciam atividade remunerada. Com o início da terapia hemodialítica, todos os entrevistados que trabalhavam não estão trabalhando atualmente.

No que se refere aos motivos que levaram ao afastamento do trabalho, os entrevistados declararam que foi decorrente da falta de condições físicas e/ou falta de tempo, cujo desgaste após as sessões de hemodiálise deixava-os impossibilitados de qualquer atividade que requeresse maior esforço físico, e o tempo que leva conectado à máquina somado ao tempo gasto até chegar ao serviço de saúde impossibilita a manutenção de uma atividade diária sistemática ${ }^{9}$.

Nesse sentido, mesmo que o usuário em hemodiálise se sinta apto fisicamente para o trabalho e almeje continuar trabalhando, seja no mercado formal, seja no informal, terá possivelmente grandes dificuldades em permanecer ou se inserir num trabalho, em decorrência da forma de organização do mundo do trabalho e da estruturação da sociedade capitalista, a qual definem rigorosas exigências para a classe trabalhadora. Entretanto, para o trabalhador informal, essa dificuldade se agrava, já que não possuem direitos trabalhistas, e, assim, ficam vulneráveis diante do afastamento do trabalho, que até o momento, era sua fonte de renda.

Diante dessa realidade do mundo do trabalho e da sua lógica acumulativa, que exige qualificação, polivalência, longa jornada de trabalho entre outras, o trabalhador que não se enquadra nesse perfil tende a ser descartado. Assim, é possível afirmar que o afastamento dos usuários em terapia hemodialítica, das atividades geradoras de renda, não se relaciona apenas ao aspecto clínico, mas também às exigências do mundo do trabalho.

Outro fator importante identificado é o tipo de atividade desempenhada pelos 13 usuários que trabalhavam antes de iniciar a terapia hemodialítica. A pesquisa identificou que as atividades exercidas por eles, em sua maioria, se caracterizam pelo uso de grande esforço físico e atividades de trabalho manuais, com exigência também de tempo para exercê-las, são elas: trabalhador doméstico (5); encanador (1); verdureiro (1); vidraceiro

\footnotetext{
${ }^{9}$ As sessões de hemodiálise são realizadas geralmente três vezes por semana por quatro horas cada. Levando em consideração uma jornada de trabalho de quarenta horas semanais, o usuário permanece aproximadamente $30 \%$ desse tempo conectado à máquina, isto equivale a um dia e meio, lembrando que este tempo deve ser realizado em dias alternados, conforme preconizado pela RDC 154 (BRASIL, 2004).
} 
(1); tratador de peixe (1); costureiro (1); auxiliar de serviços gerais (1); auxiliar de vendas (1); e professor do ensino fundamental (1).

Essas profissões apresentadas, com exceção do auxiliar de vendas e professor do ensino fundamental, caracterizam-se por atividades subalternizadas socialmente, pois são profissões que estão relacionadas, historicamente, à informalidade e à precarização da força de trabalho, sobretudo por não exigirem escolaridade para exercê-las.

De forma geral, é possível afirmar que os usuários em tratamento hemodialítico no HC-UFPE que se inseriram no BPC tinham, em sua trajetória histórica, baixa renda, baixa escolaridade, e desproteção previdenciária, eles integram o contingente que não tem acesso a garantias trabalhistas e veem como única saída a busca pelo atendimento no âmbito da assistência social, em especial o BPC, como a única via de acesso à renda.

\section{A inserção no BPC dos usuários em tratamento hemodialítico}

No que se refere ao processo de inserção no BPC pelos usuários em programa hemodialítico no HC-UFPE, a pesquisa identificou que do total de entrevistados que requereu o benefício, 58\% (11) tiveram seu processo indeferido na primeira tentativa ${ }^{10}$. Destes, todos conseguiram inserção após solicitarem uma segunda perícia.

Quando perguntados acerca dos motivos que levaram ao indeferimento, nenhum dos entrevistados soube explicar o motivo da negação, mesmo sendo informado sobre o indeferimento por meio de carta-resposta enviada pelo INSS.

Diante disso, observamos que existem dificuldades por parte dos usuários em compreender o conteúdo exposto na carta. Assim, é possível relacionar essa dificuldade ao tipo de linguagem do texto ${ }^{11}$ - a qual expressa vocábulos formais - e à pouca compreensão dos usuários, devido a sua condição subalternizada, como identificado anteriormente. Sendo assim, não tivemos dados concretos para analisar os possíveis motivos que levaram ao indeferimento, mas podemos supor que a negação possa ter sido por alguns fatores, um deles se refere à elegibilidade da pessoa com deficiência para os médicos peritos do INSS,

\footnotetext{
${ }^{10} \mathrm{O}$ BPC garante ao requerente a possibilidade de contestação, podendo recorrer diante da negativa do INSS.

${ }^{11} \mathrm{O}$ texto da carta é padronizado e utiliza recursos linguísticos formais, contendo o assunto, o tipo de benefício, o motivo específico e o detalhamento das razões do indeferimento e a correspondente fundamentação legal. 0 documento traz, ainda, como nota de rodapé, todas as exigências para o reconhecimento inicial do direito ao benefício.
} 
posto que ainda não há um consenso acerca de quem são as pessoas aptas ou não à vida independente (DINIZ; SQUINCA; MEDEIROS, 2007).

Segundo Diniz, Squinca e Medeiros (2007), numa pesquisa realizada com médicos peritos do INSS identificou-se que uma pessoa com insuficiência renal crônica seria considerada elegível para apenas $28 \%$ dos médicos. Se essa insuficiência fosse combinada à diabetes, a taxa de aprovação dobraria para $57 \%$ dos examinadores, e isso não seria causado pela presença da diabetes, mas pela combinação das duas condições, pois o que é levado em consideração é a intensidade da condição da doença crônica.

A ideia de pessoa com deficiência elegível ao BPC é aquela com uma incapacidade grave ou extremamente debilitante (DINIZ; SQUINCA; MEDEIROS, 2007). Então, pode-se entender que não basta ter DRC para ser considerado incapaz, tem que ser também considerado grave e debilitado.

Além desse fator, podemos supor que outras exigências do INSS não tenham sido cumpridas pelos usuários como, por exemplo, as documentações comprobatórias de identificação pessoal e/ou da doença, entre outras situações.

Diante disso, sugerimos novos estudos que possam traçar um perfil socioeconômico e clínico em paralelo aos critérios utilizados pelo INSS para inserção de usuários com DRC em tratamento hemodialítico, uma vez que não conseguimos identificar claramente os motivos que levaram à recusa do benefício na primeira tentativa de acesso.

Ainda no que se refere à inserção no BPC, a presente pesquisa identificou que a maioria dos usuários encontra dificuldades no acesso ao benefício. Conforme dados: $90 \%$ (17) relataram ter encontrado dificuldades no acesso ao BPC, e 10\% (2) relataram que não encontraram dificuldades no acesso.

Dentre as dificuldades perguntadas, apenas o tempo de espera do agendamento até o recebimento foi identificado como dificuldade. Esse tempo que os usuários consideraram como dificuldade esteve entre 3 e 11 meses de espera, entre estes estão os usuários que tiveram seu processo indeferido na primeira tentativa. Entretanto, em relação ao processo de requisição do benefício, e, nesse caso, referimo-nos ao processo de agendamento e perícia, os usuários relataram não ter encontrado nenhuma dificuldade.

Portanto, o tempo de espera foi a única dificuldade relatada por eles. Com isso, é possível compreender que a ênfase dada nessa dificuldade se deu pelo fato dessas pessoas 
terem iniciado a terapia hemodialítica e concomitantemente terem se afastado do trabalho, como já analisado anteriormente, mas que vale a pena retomar: dos entrevistados que trabalhavam, todos se afastaram do trabalho ao iniciar a hemodiálise. E, assim, por não conseguirem mais manter-se nas atividades geradoras de renda e, sobretudo, por não terem proteção previdenciária, ficaram dependentes financeiramente de familiares ou terceiros, durante o período de espera até conseguirem acessar o BPC.

Isso é um fator bastante agravante para a saúde e a vida desses usuários, já que, antes mesmo do adoecimento, a sua renda familiar estava aquém das condições necessárias à reprodução social adequada, como consta na tabela 2:

Tabela 2 - Caracterização da renda familiar per capta anterior ao tratamento hemodialítico. Recife, HC/UFPE, 2013.

\begin{tabular}{cc|c}
\hline Renda per capta & \multicolumn{2}{c}{ Entrevistados (N= 19) } \\
\cline { 2 - 3 } & $\mathbf{n}$ & $\mathbf{\%}$ \\
\hline Não tinham renda & 3 & $16 \%$ \\
Até 25\% do salário mínimo & 3 & $16 \%$ \\
Até 80\% do salário mínimo & 13 & $68 \%$ \\
TOTAL & 19 & $100 \%$ \\
\hline
\end{tabular}

*A maioria das rendas declaradas das famílias provém de trabalhos informais.

Fonte: Elaborada pelas autoras.

Com esses dados, percebemos a baixa condição econômica desses usuários e de sua composição familiar, que apresentavam, antes do adoecimento, a renda per capta familiar de zero à $80 \%$ do salário mínimo. Diante desses valores, podemos perceber o grau de dificuldade para essas famílias ${ }^{12}$ durante o período de espera para a inserção no BPC. Posto que essa renda familiar apresentada foi diminuída com a saída de um dos provedores, como já identificado anteriormente, dificultando ainda mais a manutenção das despesas da família.

De acordo com o Departamento Intersindical de Estatística e Estudo Socioeconômico - DIEESE, em pesquisa referente ao mês de janeiro/2013 o custo da cesta básica de alimentos $^{13}$ na cidade do Recife foi de $\mathrm{R} \$ 278,92$ (duzentos e setenta e oito reais e noventa

\footnotetext{
${ }^{12}$ Para o BPC a família é composta pelo requerente, o cônjuge ou companheiro, os pais e, na ausência de um deles, a madrasta ou o padrasto, os irmãos solteiros, os filhos e enteados solteiros e os menores tutelados, desde que vivam sob o mesmo teto (BRASIL, 2007).

${ }^{13} \mathrm{~A}$ cesta básica é composta por 12 itens, são eles: carne, feijão, arroz, leite, farinha, tomate, pão, café, banana, açúcar, óleo e manteiga (DIEESE, 2013).
} 
e dois centavos), comprometendo $44,72 \%$ do salário mínimo, apenas com alimentação. Lembrando que ainda existem gastos com moradia, educação, transporte, higiene, saúde, lazer, vestuário, entre outros.

Então, se antes de iniciar a terapia hemodialítica essas famílias já apresentavam grandes dificuldades de suprir as necessidades vitais básicas para manutenção da vida, com o início do tratamento de hemodiálise essa situação se agravou, principalmente pelas exigências características do tratamento, o que pressupõe alimentação de qualidade para responder a uma dieta específica, gastos com suplementos alimentares, gasto com transporte até a unidade de saúde etc. Portanto, com essas novas necessidades e sem poder dar continuidade à atividade remunerada que exercia, a inserção no benefício tornase uma urgência para a manutenção da sobrevivência desses usuários.

Sendo assim, o acesso ao BPC pode ser considerado indispensável para a manutenção das condições de vida e saúde dos entrevistados, que por terem se afastado do trabalho diminui a renda familiar, e não sendo protegidos da previdência social não conseguiram manter as despesas da família, nem manter as necessidades básicas adequadas que requer uma pessoa em terapia hemodialítica ${ }^{14}$.

Vale ressaltar que embora a maioria dos usuários tenham apresentado, no item analisado, uma renda familiar per capta acima de $25 \%$ do salário mínimo (superior ao critério exigido para inserção no BPC) ainda são elegíveis ao BPC, posto que essa renda apresentada provém do trabalho informal que não entra no cálculo para averiguação do benefício, além do que essa renda per capta foi diminuída com o afastamento do trabalho, como identificado anteriormente.

\section{A importância do BPC na reprodução social dos usuários em hemodiálise}

Para analisar a importância do BPC na reprodução social dos usuários em tratamento hemodialítico no HC-UFPE realizamos uma comparação da renda familiar per capta antes da entrada em terapia hemodialítica e posterior à inserção no BPC, para, assim,

\footnotetext{
${ }^{14}$ As necessidades básicas para esses usuários se referem, principalmente, à alimentação específica com alguns suplementos alimentares (necessários quando não conseguem atingir às necessidades nutricionais por meio da alimentação), bem como o transporte para se deslocar (três vezes por semana) até o local da hemodiálise, que requer recursos financeiros.
} 
identificarmos quantos tiveram sua renda aumentada e quantos permaneceram com a mesma renda, conforme o gráfico 2:

Gráfico 2 - Modificação da renda familiar per capta com a inserção no BPC. Recife, HC/UFPE, 2013.

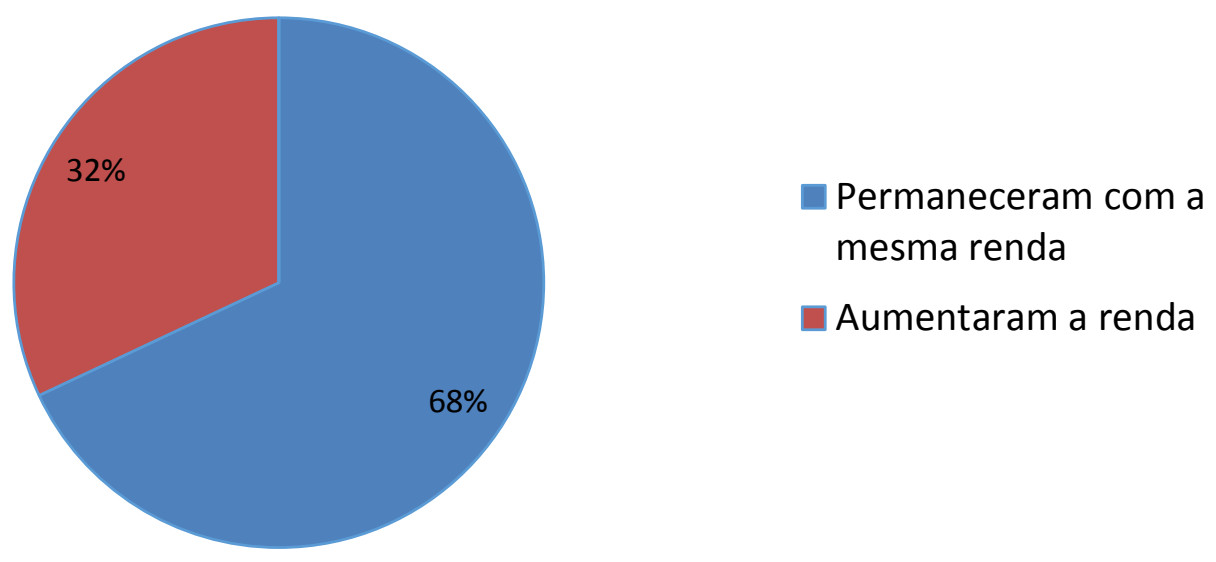

*Em nenhum dos casos houve diminuição na renda.

Fonte: Elaborado pelas autoras.

Esse gráfico aponta que $68 \%$ dos entrevistados não aumentaram sua renda, permanecendo a mesma antes de iniciar o tratamento hemodialítico, vale salientar que esse percentual equivale a 13 entrevistados, que são os mesmos que exerciam atividade remunerada antes de iniciarem a terapia hemodialítica.

Portanto, nesse caso, o BPC apenas substituiu a renda que eles recebiam enquanto trabalhavam, que já não era suficiente para a manutenção das necessidades vitais básicas, como analisado anteriormente, posto que a maioria deles se integra famílias numerosas e pauperizadas, na qual seus membros também não tiveram acesso ao trabalho formal protegido. Sendo assim, a dificuldade para a manutenção da sobrevivência permanece a mesma, mas com um agravante que é o enfrentamento de situações peculiares ao tratamento hemodialítico.

Entretanto, 32\% dos entrevistados passaram a ter renda. Vale salientar que esse percentual equivale a 6 entrevistados que são os mesmos que não exerciam nenhuma atividade remunerada antes de iniciar a terapia hemodialítica. Isso reflete uma melhor situação econômica que leva a uma melhora nas condições de vida desses usuários. 
Nesse sentido, o benefício tem uma representação importante na vida desses usuários, a qual, muitas vezes, acaba se tornando central para a reprodução social de toda a família. Como podemos observar nas respostas dos entrevistados quando perguntados acerca do destino da renda do benefício, conforme o gráfico 3:

Gráfico 3 - Caracterização do uso da Renda do BPC. Recife, HC/UFPE, 2013.

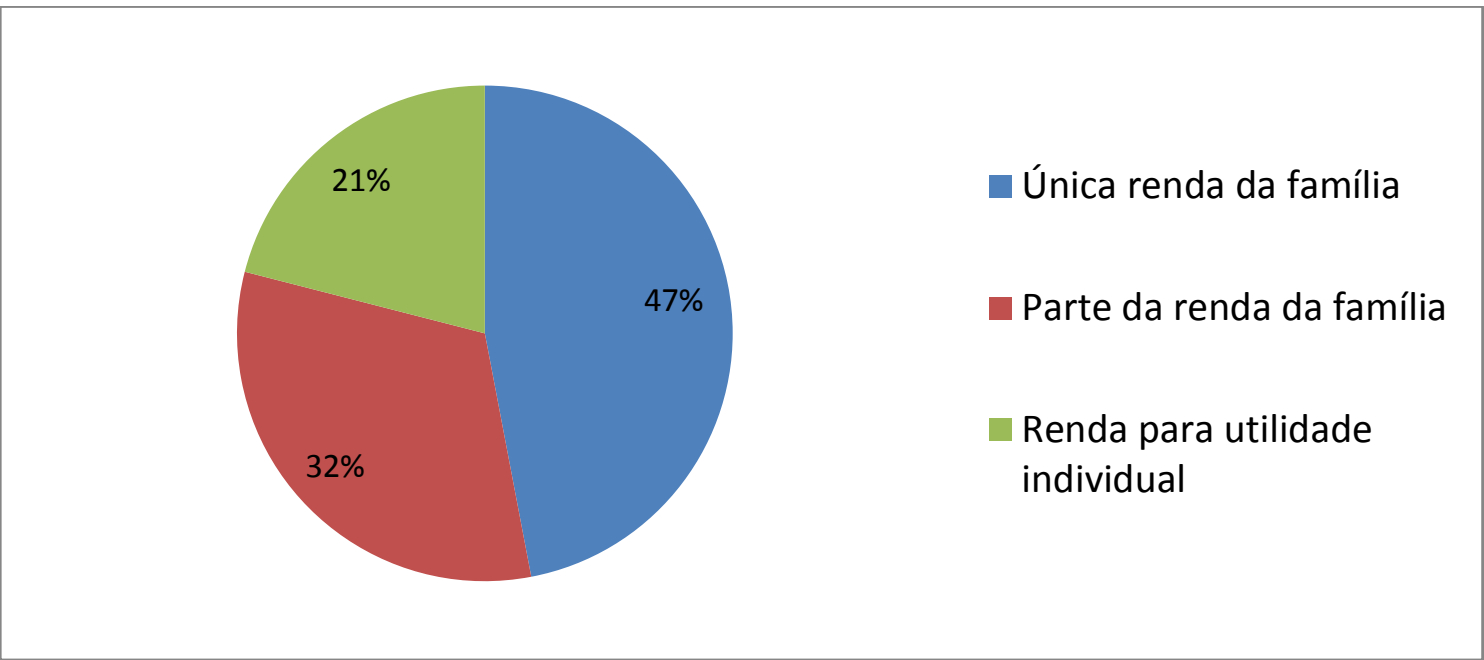

Fonte: Elaborado pelas autoras.

Esse gráfico mostrou que $47 \%$ dos entrevistados tem o BPC como a única renda da família; para $32 \%$ o benefício ajuda na manutenção das despesas, pois soma com outros proventos da família; e apenas $21 \%$ o destinam para o uso individual.

Quando perguntados se o BPC era suficiente para suprir suas necessidades vitais básicas, todos responderam que "não", inclusive àqueles que têm o benefício destinado apenas para uso individual.

Diante disso, é pertinente lembrar que um salário mínimo, se observar a realidade, não possibilita a nenhuma família a reprodução social nas condições adequadas, embora o preceito Constitucional afirme que o salário mínimo fixado em lei deva ser capaz de atender às necessidades vitais básicas de uma família, tais como: alimentação, moradia, saúde, educação, vestuário, higiene, transporte, lazer e previdência social (BRASIL, 2006). Para o DIEESE (2013) o salário mínimo necessário para atender às necessidades vitais básicas de uma família ${ }^{15}$ deveria ser de $\mathrm{R} \$ 2.873,56$ (dois mil oitocentos e setenta e três reais e

\footnotetext{
${ }^{15}$ Para o DIEESE (2013), a família considerada para o cálculo é composta por 2 adultos e 2 crianças.
} 
cinquenta e seis centavos), no ano de 2013. Assim, é possível assegurar que o atual salário mínimo no valor de $\mathrm{R} \$ 678,00$ não supre as necessidades de uma família e, por isso, o benefício, apesar de ser uma conquista importante, por si só não consegue responder às necessidades de reprodução social do usuário em hemodiálise, muito menos de sua família.

No entanto, quando perguntados acerca da importância do benefício todos responderam que o BPC é a fonte de renda mais importante. Afinal, para esses usuários o BPC significa a segurança de uma renda mensal, que supre, de certo modo, as necessidades imediatas, prevenindo a pobreza extrema.

Diante disso, identificamos impactos positivos na vida desses beneficiários e das suas famílias, uma vez que os usuários que não tinham renda alguma passaram a prover seu próprio sustento e/ou ajudar nas despesas da família, e mesmo àqueles que mantiveram a mesma renda, o benefício também foi positivo, já que proporcionou a manutenção do estado econômico, não havendo diminuição na renda em nenhum dos casos aqui pesquisados.

\section{Considerações finais}

Os resultados da presente pesquisa mostraram que o perfil dos sujeitos entrevistados tende para uma condição de pauperização, baixa escolaridade e profissões subalternizadas, principais expressões da questão social na contemporaneidade. Outro importante elemento identificado foi a impossibilidade dos usuários em manterem-se no trabalho, que se relaciona não apenas às limitações impostas pelo tratamento hemodialítico, mas também à lógica das relações de trabalho que define diversas exigências ao trabalhador, dificultando, assim, a inserção de pessoas que pela condição clínica, pelo tempo limitado e pela falta de qualificação não conseguem espaço no mercado de trabalho e assim são descartadas dele.

Outro resultado significativo foi a dificuldade no acesso ao BPC, referente ao tempo de espera desde o agendamento até o recebimento, o que fragilizou a situação do usuário que parou de trabalhar e manteve-se sem renda nesse período de tempo até conseguir ser inserido no benefício. Dessa forma, a pesquisa revelou que o BPC é o recurso mais importante para o suprimento das necessidades básicas dos usuários e de suas famílias. 
Por isso, entendemos ser absolutamente necessária à destinação do BPC aos segmentos aqui estudados, uma vez que o benefício atende a diversas demandas, embora imediatas, mas que garantem a sobrevivência dos usuários.

Nesse sentido, a criação do BPC como benefício da política de assistência social é considerada uma importante conquista da sociedade, um avanço para os direitos sociais, por ter superado a lógica contributiva e se transformado numa perspectiva mais inclusiva.

No entanto, a expressão contraditória da assistência social, em especial do BPC, conforme demonstrado pelos dados da pesquisa, evidencia a precarização, a seletividade e a focalização desse benefício.

Para finalizar, as dimensões analisadas neste artigo não esgotam as possíveis interações entre os usuários em hemodiálise e o BPC, bem como as tendências da política de assistência social. Entretanto, os conceitos levantados aqui apontam as fundamentais expressões da fragilização dos usuários em terapia hemodialítica que necessitam do BPC para se reproduzirem socialmente.

\section{Referências}

ANTUNES, R. As metamorfoses no mundo do trabalho. In: . Adeus ao trabalho? São Paulo: Cortez, 1995. p. 47-65

BRASIL. Lei 8.742 de 7 de dezembro de 1993. Dispõe sobre a organização da Assistência Social e dá outras providências. Disponível em:

<http://www.planalto.gov.br/ccivil_03/leis/ I8742.htm>. Acesso em: 20 jun. 2012.

. Ministério da Saúde. Conselho Nacional de Saúde. Resolução no 196, de 10 de outubro de 1996. Diretrizes e normas regulamentadoras de pesquisas envolvendo seres humanos. Brasília, 1996. Disponível em: <http://dtr2004.saude.gov.br/susdeaz/ legislacao/arquivo/Resolucao_196_de_10_10_1996.pdf>. Acesso em:

. RDC n. 154 de junho de 2004. Estabelece o regulamento técnico para o funcionamento dos serviços de diálise. Disponível em: <http://portal.anvisa.gov.br/ wps/content/Anvisa+Portal/Anvisa/Inicio/Laboratorios/Assuntos+de+Interesse/Legislaca o/Resolucao+da+Diretoria+Colegiada+-+RDC>. Acesso em: 10 fev. 2013.

. Constituição da República Federativa do Brasil. 5. ed. Porto Alegre, 2006.

. Decreto n. 6.214, de 26 de setembro de 2007. Regulamenta o benefício de prestação continuada da assistência social devido à pessoa com deficiência e ao idoso. Diário Oficial da União, Brasília,Seção 1, 28 set. 2007, p.16. Disponível em: 
<http://www.planalto.gov.br/ccivil_03/_ato2007-2010/2007/decreto/d6214.htm>. Acesso em: 20 jun. 2012.

Ministério de Desenvolvimento Social. Renda mensal vitalícia (RMV). Brasília, 2013. Disponível em: <http://www.mds.gov.br/assistenciasocial/beneficiosassistenciais/ renda-mensal-vitalicia-rmv> Acesso em: 15 mar. 2013.

BUSS, P. M; PELLEGRINI FILHO, A. A saúde e seus determinantes sociais. Physis Revista Saúde Coletiva, Rio de Janeiro, v. 17, n. 1, p. 77-93, 2007. Disponível em:

<http://www.scielo.br/pdf/physis/v17n1/v17n1a06.pdf>. Acesso em: 22 out. 2012.

DIEESE - DEPARTAMENTO INTERSINDICAL DE ESTATÍSTICA E ESTUDOS

SOCIOECONÔMICOS. Balanço das negociações dos reajustes salariais do 1o semestre de 2013. Disponível em: <http://www.dieese.org.br/esp/estPesq62balNegocia1 sem2013.pdf> Acesso em:2 maio 2013.

DINIZ, D.; SQUINCA, F.; MEDEIROS, M. Qual deficiência? Perícia médica e assistência social no Brasil. Cad. Saúde Pública, Rio de Janeiro, v. 23, n. 22, p. 2589-2596, 2007.

IAMAMOTO, M. A questão social no capitalismo. Temporalis, Brasília, ano 2, n. 3,2001.

IVO, A. B. I.; SILVA, A. B. A. O hiato do direito dentro do direito: os excluídos do BPC. Revista Katálysis, Florianópolis, v. 14, n. 1, p. 32-40, 2011.

LUKÁCS, G. Ontologia do ser social: Os princípios ontológicos fundamentais de Marx. Tradução de Carlos Nelson Coutinho. Livraria Ciências Humanas, São Paulo, 1979.

MARTÍNEZ, B. B. et al.Desigualdade social em pacientes renais crônicos. Revista Brasileira de ClínicaMedica, São Paulo, v. 9, n. 3, p.195-199, maio/jun. 2011.

MARX, K. Legislação fabril. Cláusulas sanitárias e educacionais e sua generalização na Inglaterra. In: O capital. São Paulo: Abril Cultural, 1984. v. 1, t. II.

MEDEIROS, M. Reflexões sobre a versão em português da classificação internacional de funcionalidade, Incapacidade e saúde. Caderno de Saúde Pública, Rio de Janeiro, v. 23, n. 10, p. 2507-2510, 2007.

MINAYO, M. C. S. O desafio do conhecimento: pesquisa qualitativa em saúde. 2. ed. São Paulo: Hucitec, 1993.

MOTA, A. E. Cultura da crise e seguridade social: um estudo sobre as tendências da previdência e da assistência social brasileira nos anos 80 e 90. São Paulo: Cortez,2000.

NETTO, J. P. FHC e a política social: um desastre para as massas trabalhadoras. In: LESBAUPIN, Ivo (Org.). O desmonte da nação: balanço do governo FHC. 2. ed. Petrópolis: Vozes, 1999. p. 75-89.

OLIVEIRA, I. A; SEVERO, R. R; NASCIMENTO, S. G. Conhecer a realidade para viabilizar direitos: caracterização socioeconômica dos pacientes em hemodiálise do Hospital 
Universitário do Município do Recife. In: CONGRESSO BRASILEIRO DE ENFERMAGEM EM NEFROLOGIA, 14., 2008, Curitiba. Anais... Curitiba, 2008. p. 152.

PALOMBINI, D. V; MANFRO, R. C; KOPSTEIN, J. Aspectos emocionais dos pacientes em hemodiálise crônica. Revista da Associação Médica Brasileira, São Paulo, v. 31, n. 5/6, p. 81-84, maio/jun. 1985.

PEREIRA, P. A. Política de assistência social no Brasil: avanços e retrocessos. Caderno do CEAM, Brasília, ano 3, n. 11, 2002.

RIBEIRO, R.C; Helú M; OLIVEIRA, G. A. S. A; RIBEIRO, D. F; BERTOLIN, D. C; CESARINO, C. B; LIMA, L. C. E. Q; OLIVEIRA, S. M. Caracterização e etiologia da insuficiência renal crônica em unidade de nefrologia do interior do Estado de São Paulo. Acta paul. enferm, São Paulo, v. 21, 2008.

ROMÃO JÚNIOR, J. E. Os 60 anos da hemodiálise no Brasil: da criação do rim artificial à consolidação do tratamento em solo nacional. Nefro SP, São Paulo, ano 5, n. 16, jul./set. 2009. Disponível em: <http://www.sonesp.org.br/nefrosp/pdf/090909.pdf> Acesso em: 10 fev. 2012.

SBN - SOCIEDADE BRASILEIRA DE NEFROLOGIA. Censo de diálise 2010. São Paulo, 2011. Disponível em: <http://www.sbn.org.br/leigos/index.php?censo>. Acesso em: 7 dez.2012.

SOARES, R. C. Aids, trabalho e proteção social: elementos para uma leitura crítica das condições de vida dos pacientes do Hospital Oswaldo Cruz. 2000. Dissertação (Mestrado em Serviço Social) - Universidade Federal de Pernambuco, Recife, 2000.

SONESP - SOCIEDADE DE NEFROLOGIA DO ESTADO DE SÃO PAULO. Especial: hemodiálise no brasil chega aos 60. Nefro SP, ano 5, v. 16, jul./set. 2009. Disponível em:

<http://www.sonesp.org.br/nefrosp/pdf/090909.pdf> Acesso em: 10 jan. 2013

UNRUH, M. et al. Sleep quality and clinical correlates in patients on maintenance dialysis. Clinical Nephrology, Munchen, v. 59, n. 4, p. 280-288, Apr. 2003.

Recebido em: 16/10/2013

Aprovado em: 15/09/2014 